\title{
El umbral de gravedad suficiente del artículo 17 (1) (d) del Estatuto de Roma*
}

\author{
Miguel Andrés Hoyos García** \\ Recibido: 09 de septiembre 2013 - Revisado: 10 de octubre 2013
}

- Aprobado: 22 de octubre 2013

\section{Resumen}

La Corte Penal Internacional puede conocer de crímenes dentro su competencia, cuando se cometan en un Estado Parte del Estatuto de Roma o que acepte su jurisdicción.

No obstante, es necesario que tales casos cumplan con los requisitos del artículo 17 del Estatuto, entre ellos el numeral 1 literal d, que exige la inadmisibilidad cuando el asunto no sea de gravedad suficiente.

Sin embargo, el Estatuto en ningún momento definió o dio parámetros para determinar qué se debía entender por "gravedad suficiente", generando un vacío que se ha intentado llenar a través de los criterios de admisibilidad adoptados por la Office of the Prosecutor (OTP) y los pronunciamientos de la SCP (Sala de Cuestiones Preliminares) -Pre-Trial Chamber-, los cuales presentan falencias.

Palabras clave: gravedad, criterio, admisibilidad, sistemático, masivo, complementariedad, objetivo, subjetivo, intereses jurídicos.

"Artículo de Investigación. Producto del trabajo de grado para obtener el título de abogado de la Universidad Santo Tomás Bogotá D.C. Proyecto de Investigación titulado El umbral de gravedad suficiente del Artículo 17 (1) (d) del Estatuto de Roma. Diciembre de 2012.

* Abogado de la Universidad Santo Tomás. 


\title{
THE THRESHOLD OF SUFFICIENT SEVERITY OF ARTICLE I 7 (I) (D) of the Rome Statute
}

\begin{abstract}
The International Criminal Court -ICC may investigate and prosecute crimes within the jurisdiction of the Court in accordance with the Rome Statute and committed in a signatory State or in States that has accepted ICC jurisdiction.

In order to be selected, a case must meet the issues of admissibility as stated in the article 17 , and particularly a "sufficient gravity" condition, but the Rome Statute did not defined what exactly meant by that.

Several attempts have been made to define it based on gravity criteria and an objective threshold for prosecution given by the Office of The Prosecutor and the Pre-Trial Chamber, but still some legal doubts remain.
\end{abstract}

Keywords: gravity, criterion, admissibility, systematic, widespread, complementarity, object, subject.

\section{LIMIAR GRAVIDADE SUFICIENTE DO ARTIGO I7 (I) (D) Estatuto de Roma}

\section{Resumo}

O Tribunal Penal Internacional tem jurisdição de crimes dentro de sua jurisdição, se cometido por um Estado Parte no Estatuto de Roma ou aceitaram sua jurisdição.

No entanto, esses casos precisam cumprir os requisitos do artigo 17 do Estatuto, incluindo parágrafo 1 letra d, o que requer inadmissível quando o caso não é de gravidade suficiente.

No entanto, a lei em nenhum momento ele definido ou parâmetros para determinar o que deve ser entende por "gravidade suficiente", gerando um vácuo que tem sido tentado para preencher através dos critérios de elegibilidade adotados pela OTP exercício do theProsecutor-e os pronunciamentos da Câmara-, SCP-pré-julgamento que têm deficiências.

Palavras-chave: gravidade, criterion, elegibilidade, sistemática, missa, complementaridade, objetivo, interesses subjetivos, legais. 


\section{Introducción}

La Corte Penal Internacional (en adelante la Corte), es el primer tribunal internacional con capacidad para juzgar personas naturales y con un carácter permanente (a diferencia de los tribunales $a d-h o c$ ). Sin embargo, para que pueda conocer de crímenes de su competencia necesita que se cumplan unos requisitos conocidos como cuestiones de admisibilidad, contenidos en el artículo 17 del Estatuto de Roma y que son: el principio de complementariedad y el umbral de gravedad suficiente.

El principio de complementariedad, contenido en el inciso décimo del preámbulo, el artículo 1 y el artículo 17 (1) (a) al (c) del Estatuto de Roma, señala que la Corte puede entrar a conocer de crímenes de su competencia que se hayan cometido en un Estado Parte del Estatuto o en un Estado que haya aceptado su jurisdicción; cuando dicho territorio no esté dispuesto o no pueda investigar o enjuiciar a presuntos responsables de la comisión de dichos crímenes.

Por otro lado, el umbral de gravedad suficiente, plantea que la Corte puede conocer de crímenes de su competencia acaecidos en un Estado Parte o en alguno que haya aceptado su jurisdicción, si el asunto es de gravedad suficiente. Empero, el criterio de gravedad suficiente del artículo 17 (1) (d) que se requiere para la admisibilidad de una investigación por parte de la Corte, no se encuentra definido en el Estatuto, como tampoco en los elementos de los crímenes ni en las reglas de procedimiento y prueba. Es decir, el criterio de gravedad suficiente no fue determinado por el legislador del Estatuto de Roma.

De esta manera, teniendo en cuenta que el Estatuto tiene un juicio que resulta ser supremamente vago, es menester determinar qué se debe entender por el umbral de gravedad suficiente al que alude el artículo 17 (1) (d) del Estatuto.

Se acudirán a los planteamientos que sobre el tema hizo la Comisión de Derecho Internacional, asimismo, se estudiarán los planteamientos y las decisiones emitidas por las Sala de Cuestiones Preliminares y las Sentencias de la Corte.

Al respecto, es importante resaltar que tanto la Oficina del Fiscal como la Sala de Cuestiones Preliminares, han intentado determinar el umbral de gravedad suficiente a través de valoraciones cuantitativas y cualitativas, no obstante, aún presenta bastantes dificultades.

Además, es importante tener presente que un requisito para que la pueda conocer de los crímenes de su competencia contenidos en el artículo 5 del Estatuto, es decir, genocidio, lesa humanidad, guerra y agresión; cada uno requiere de unos 
presupuestos o elementos exigentes que los componen. En ese orden de ideas, cabe preguntarse si la gravedad de los crímenes puede estar contenida dentro de los elementos de contexto de los crímenes o si por el contrario, la gravedad es independiente. Lo anterior, es de significativa relevancia ya que de demostrarse el presupuesto de que la gravedad está contenida en los elementos de los crímenes, sustentar la gravedad de los crímenes por aparte resultaría ser fútil.

El presente estudio, es el resultado de la tesis de grado para optar al título de abogado en la Universidad Santo Tomás, el cual recibió la calificación de tesis Meritoria. La investigación fue realizada a través de la técnica documental. El tipo de investigación teórico-documental escogida fue la histórica.

\section{La Comisión de Derecho Internacional}

\subsection{Antecedentes del criterio de gravedad}

Cuando la Comisión de Derecho Internacional estaba redactando el proyecto de código de delitos contra la paz y la seguridad de la humanidad, resaltó que la Convención sobre la imprescriptibilidad de los crímenes de guerra y de lesa humanidad consideraba únicamente imprescriptibles aquellos crímenes de guerra de carácter grave (Naciones Unidas, 1983, p. 20; Hoyos, 2012, p. 36). Adicionalmente, la Comisión de Derecho Internacional al revisar los Convenios de Ginebra de 1949, encontró que las medidas obligatorias que se veían los Estados a adoptar, estaban relacionadas con establecer sanciones penales contra las infracciones graves. Así, los artículos 129 y 130 de la Convención de Ginebra de 1949, aducen:

ARTÍCULO 129. SANCIONES PENALES. I. GENERALIDADES. Las Altas Partes Contratantes se comprometen a tomar todas las oportunas medidas legislativas para determinar las adecuadas sanciones penales que se han de aplicar a las personas que hayan cometido, o dado orden de cometer, una cualquiera de las infracciones graves contra el presente Convenio definidas en el artículo siguiente. Cada una de las Partes Contratantes tendrá la obligación de buscar a las personas acusadas de haber cometido, u ordenado cometer, una cualquiera de las infracciones graves y deberá hacerlas comparecer ante los propios tribunales, sea cual fuere su nacionalidad.

(...) 
ARTÍCULO 130. II. INFRACCIONES GRAVES. Las infracciones graves a las que se refiere el artículo anterior son las que implican uno cualquiera de los actos siguientes si se cometen contra personas o bienes protegidos por el Convenio: el homicidio intencional, la tortura o los tratos inhumanos, incluidos los experimentos biológicos, el hecho de causar deliberadamente grandes sufrimientos o de atentar gravemente contra la integridad física o la salud, el hecho de forzar a un prisionero de guerra a servir a las fuerzas armadas de la Potencia enemiga, o el hecho de privarlo de su derecho a ser juzgado legítima e imparcialmente según las prescripciones del presente convenio. (III. Convenio de Ginebra relativo al trato debido a los prisioneros de guerra, 1949; Hoyos, 2012, pp. 36-37).

No obstante, ninguno de los IV Convenios de Ginebra de 1949 ni los Protocolos adicionales de 1977 o la Convención sobre la imprescriptibilidad de los crímenes de lesa humanidad y de guerra, definen qué se debe entender por infracción grave.

\subsubsection{El adjetivo gravedad}

El Relator Especial, el Sr. Thiam, precisó que la gravedad extrema era un criterio. Señalando además que extraer un criterio es sumamente complejo, pero que una vez extraído, no se puede confundir con una definición. Una definición, busca ser lo más precisa posible, mientras que un criterio "no es más que un signo para distinguir un objeto, sin que tal signo permita necesariamente distinguir los elementos constitutivos de ese objeto" (Naciones Unidas, 1984, p. 94; Hoyos, 2012, p. 37).

\subsubsection{Los elementos de la gravedad}

La Comisión resaltó que el criterio de gravedad permitía determinar qué crímenes atentaban contra la paz y la seguridad de la humanidad, sin embargo, dicho criterio resultaba ser muy vago, aunado al hecho de que hasta ese momento no se habían determinado los signos necesarios para que a partir de ellos se pudieran identificar y plasmar, de manera razonada, los crímenes que debían ser considerados como los más graves.

Para la Comisión los adjetivos "esencial" y "fundamentales" contenidos en el artículo 19 párrafo 2 sobre la Responsabilidad de los Estados, definen la escala de la gravedad, que deriva en dos criterios, el objetivo y el subjetivo. El criterio objetivo es el interés jurídico fundamental de la comunidad internacional. El criterio 
subjetivo, es la apreciación que se hace del crimen. (Naciones Unidas, 1983, p. 154; Hoyos, 2012, p. 38).

Para el año de 1985, la Comisión de Derecho internacional en un estudio sobre "el sentido de la noción del delito contra la paz y la seguridad de la humanidad" (Naciones Unidas, 1985, p. 70), adujo que la gravedad podía ser apreciada en función de unos elementos objetivos y subjetivos. (Naciones Unidas, 1985, p. 71; Hoyos, 2012, p. 38).

Los elementos subjetivos se pueden apreciar en función de la intencionalidad, del móvil, de la conciencia del autor de la violación, de su personalidad, entre otros. Por el contrario, los elementos objetivos se pueden apreciar en función del interés o del bien jurídicamente tutelado. (Naciones Unidas, 1985, Vol p. 71; Hoyos, 2012, p. 39).

De esta manera,

Para la Comisión esa subjetividad del criterio de gravedad, podía deducirse en función de la crueldad o barbarie del crimen; o de la amplitud de sus efectos, como el carácter masivo de los crímenes; o por su intención, tal como requiere el crimen de genocidio. En todo caso, estos crímenes vulneran los fundamentos de las sociedad humana. (Hoyos, 2012, p. 39; Naciones Unidas, 1987, p. 2).

Lo anterior, con el objetivo de que el proyecto de código de crímenes contra la paz y la seguridad de la humanidad incluyera únicamente los más graves.

Ahora bien, si el elemento objetivo es el “interés jurídico" (Ramírez, 2012) que se busca proteger, entre más importante sea este, más grave será la violación. En ese orden de ideas y teniendo en cuenta que de conformidad con el inciso tercero del preámbulo, el Estatuto Roma pretende proteger la paz, la seguridad y el bienestar de la humanidad (Estatuto de Roma, 2013). Son estos intereses fundamentales los que constituyen el elemento objetivo del criterio de gravedad.

\subsubsection{Las violaciones de derechos humanos y los crímenes contra la paz y la seguridad de la humanidad}

El proyecto de código de crímenes contra la paz y la seguridad de la humanidad pretendía castigar únicamente aquellos crímenes que fueran considerados como de 
gravedad extrema, en consecuencia, estas conductas requerían ser inclusive mucho más graves que una violación de derechos humanos (Hoyos, 2012, p. 44).

Así, el señor Ni, miembro de la Comisión, señaló, como aparece en Naciones Unidas (1984, p. 17), que los crímenes contra la paz y la seguridad de la humanidad

se distinguen de las demás infracciones por las consecuencias que tiene no sólo para los individuos, sino también para los intereses fundamentales de determinados grupos e instituciones, con lo que pone en peligro los derechos e intereses fundamentales de toda la humanidad.

Asimismo, la doctrina, aunque tiempo después, validó esta afirmación al señalar que "otro enfoque para determinar el alcance del derecho penal internacional es la mirada a los valores que son protegidos por las prohibiciones del derecho internacional" (Hoyos, 2012, p. 44; Cryer, Friman, Robinson, Wilmshurst, 2007, p. 4). De esta manera, son crímenes internacionales, aquellas conductas que violan los intereses fundamentales protegidos por el derecho internacional. (Cryer et al., 2007, p. 4; Hoyos, 2012, p. 44)

Para la Comisión, una de las distinciones entre las violaciones a los derechos humanos y los crímenes contra la paz y la seguridad de la humanidad, radicaba en que los primeros afectan derechos fundamentales de los individuos, los segundos por el contrario, afectan a todos los seres humanos. (Naciones Unidas, 1984, p. 97; Hoyos, 2012, p. 45).

De esta manera, uno de los mecanismos para determinar cuando un delito afecta a toda la humanidad, y por ende, puede ser tratado como crimen contra la paz y la seguridad de la humanidad, es a través de la violación del interés jurídico afectado (Hoyos, 2012, p. 45).

\subsubsection{Viabilidad del criterio de gravedad}

Cuando se estaba discutiendo la explicación de los crímenes contra la paz y la seguridad de la humanidad, la Comisión de Derecho Internacional entró en un debate consistente en si los crímenes debían estar compuestos de una definición general o si por el contrario, debían estar enumerados (Naciones Unidas, 1987, p. 6; Hoyos, 2012, p. 46). Lo anterior, era de bastante relevancia para el tema objeto 
del presente estudio, muestra de ello radicaba en que se plantearon dos posiciones opuestas sobre la gravedad suficiente. Unos señalaban que incluir el criterio de gravedad en el proyecto de código era sumamente importante, ya que únicamente se iban a investigar aquellos crímenes considerados como de gravedad extrema. No obstante, otros, como el Relator Especial de la Comisión, planteaban que la gravedad estaba implícita en la definición de los crímenes. (Naciones Unidas, 1987, p. 6; Hoyos, 2012, p. 46).

Para el año de 1996, la Comisión reconoció que no había una definición concreta de crimen contra la paz y la seguridad de la humanidad. Sin embargo, concluía que no era imperativa dicha definición, toda vez que los crímenes que iban a ser incluidos en el proyecto de código estaban enumerados. (Naciones Unidas, 1996, p. 38; Hoyos, 2012, p. 48). La enumeración de los crímenes se encontraba en la segunda parte del proyecto de código. (Hoyos, 2012, p. 48)

\subsubsection{Los crímenes de lesa Humanidad en la Comisión de Derecho Internacional}

Cuando se estaban discutiendo los crímenes de lesa humanidad, se suscitó una controversia sobre el término humanidad, pues de ello dependía lo que el código pretendía proteger. En este punto, hubo dos posturas diferentes, la primera optaba por proteger los valores de la persona humana, y por ende, no era necesaria la masividad de los crímenes. Por el contrario, otros miembros de la Comisión, alegaban que los crímenes contra la humanidad suponían un carácter masivo. (Naciones Unidas, 1986; Hoyos, 2012, p. 49).

La polémica venía precedida por unos precedentes jurisprudenciales. La primera posición, de conformidad con la ley nro. 10 del Consejo de Control Aliado, la cual establecía "el bien jurídico protegido por esta ley es el hombre en su valor moral de ser humano con todos los derechos que le son manifiestamente reconocidos por el conjunto de los pueblos civilizados" (Naciones Unidas, 1986, p. 94). Postura sustentada por un fallo del Tribunal Supremo de la Zona Británica, que manifestaba:

[L]a ley nro. 10 se inspira en la idea de que existen en la esfera de las naciones civilizadas ciertas normas de conducta [...] que son tan esenciales para la coexistencia de la humanidad y la existencia de todo individuo que ningún Estado [...], puede dejar de reconocer. (Naciones Unidas, 1986, p. 94) 
Sin embargo, la segunda posición, argumentada por los tribunales militares estadounidenses, establecía que los crímenes que eran considerados como de lesa humanidad, debían tener un carácter masivo, y por lo tanto, los casos aislados quedaban excluidos de ser considerados como crímenes contra la humanidad. (Naciones Unidas, p. 94).

Así mismo, el Comité Jurídico de la Comisión de las Naciones unidas, apoyando lo planteado por los tribunales militares estadounidenses, sostuvo:

Los delitos aislados no entrañan la noción de crímenes contra la humanidad. En principio sería necesaria una acción masiva y sistemática, en particular si estuviese revestida de autoridad, para transformar un crimen de derecho común (...) en crimen de lesa humanidad (...). (Naciones Unidades, 1986, p. 94).

Fue esta postura la que más fuerza tomó y para el año de 1986 la Comisión toma una posición al considerar que el carácter masivo es un elemento necesario para los crímenes contra la paz y la seguridad de la humanidad. Asimismo, algunos miembros de la Comisión como el señor McCaffrey consideraban que el elemento sistemático, que también se requería para los crímenes contra la humanidad, podía llegar a ser incluso más importante que el elemento masivo, ya que estos crímenes sistemáticos se encuadran dentro de un plan de conjunto. (Naciones Unidas, 1986, p. 127). Sin embargo, estas conductas estaban revestidas o inspiradas en móviles políticos, raciales, religiosos o culturales (Naciones Unidas, 1989, p. 93). Es decir, los crímenes contra la humanidad, están dotados de fines ideológicos, por lo tanto dan lugar a persecuciones sistemáticas contra grupos de personas (Hoyos, 2012, p. 51).

Ahora bien, hablando del crimen de lesa humanidad catalogado como "otros actos inhumanos", la Comisión adujo que este implicaba la violación sistemática o generalizada contra una población civil por motivos nacionales, políticos, étnicos o religiosos. (Naciones Unidas, 1994, p. 42).

Así, de conformidad con lo plasmado, es menester tener en cuenta que para la Comisión, los crímenes de lesa humanidad siempre se realizan contra una población civil, basados en unas razones o móviles mediante los cuales el sujeto activo, ya sea el promotor o ejecutor del ataque ve liberada su conciencia o justificada su conducta por motivos políticos, nacionales, étnicos, religiosos o culturales, y estas conductas son realizadas de marea sistemática o masiva. 


\subsubsection{Los crímenes de guerra en la Comisión de Derecho Internacional}

Cuando se estaba analizando la gravedad que debían tener los crímenes de guerra para que fueran incluidos dentro del proyecto de código de crímenes contra la paz y la seguridad de la humanidad, el Relator Especial de la Comisión, señaló que el criterio de gravedad hacía parte de las leyes internacionales tal como se encontraba estipulado en el Convenio de Ginebra III de 1949, relativo al trato debido a los prisioneros de guerra, en sus artículos 129 y 130, y en el Protocolo I Adicional a los Convenios de Ginebra de 1949, relativo a la protección de las víctimas de los conflictos armados internacionales de 1977, donde el párrafo 5 del artículo 84 reza "sin perjuicio de la aplicación de los Convenios y del presente protocolo, las infracciones graves de dichos instrumentos se considerarán como crímenes de guerra" (Protocolo I adicional a los Convenios de Ginebra de 1949 relativo a la protección de las víctimas de los conflictos armados internacionales, 1977). De esta manera, la Comisión manifestaba que se debían considerar como crímenes de guerra aquellas conductas que fueran consideradas como las más graves. Sin embargo, algunos miembros como el Relator Especial, planteaban que se debía entender como crimen de guerra cualquier violación a las leyes de la guerra. (Naciones Unidas, 1989, p. 5; 1951, p. 136).

Así, la discusión en la Comisión sobre los crímenes de guerra se centraba en dos posturas, aquellos que consideraban que únicamente los crímenes de guerra más graves podían ser objeto del proyecto de código de crímenes contra la paz y la seguridad de la humanidad; y aquellos que consideraban que cualquier infracción constituía un crimen de guerra, tal como se evidenció en las sentencias del Tribunal Militar Internacional. (Naciones Unidas, 1989, p. 5)

$\mathrm{Al}$ respecto, la Comisión señaló que la diferencia entre los crímenes de guerra y las infracciones graves, se encontraba en que estas últimas se aplican de conformidad a los Convenios de Ginebra de 1949 y del Protocolo I adicional a los Convenios de Ginebra, sin embargo, los crímenes de guerra van mucho más allá. Por lo tanto, el hecho de que el proyecto de código de crímenes contra la paz y la seguridad de la humanidad defina los crímenes de guerra como una violación grave a las leyes y usos de la guerra, y no como una infracción grave, da muestras de haber querido ir más allá y no limitarse únicamente a los Convenios de Ginebra de 1949 y los Protocolos Adicionales a los Convenios de Ginebra de 1977. (Naciones Unidas, 1989, p. 88). 
Para el año de 1996, la Comisión de Derecho Internacional, redactó en su artículo 20 (Hoyos, 2012, pp. 114 - 118) las conductas consideradas como crímenes de guerra, precedidas de una definición general, en la cual se contextualizaba la conducta dentro de unos requisitos para que pudiera ser catalogado el acto como crimen de guerra. (Hoyos, 2012; Naciones Unidas, 1996, p. 57).

\title{
2. El requisito de admisibilidad en la Comisión de Derecho Internacional y en la Conferencia de Plenipotenciarios de las Naciones Unidas sobre el establecimiento de una Corte Penal Internacional
}

E1 9 de febrero de 1993, la Asamblea General de las Naciones Unidas solicitó a la Comisión de Derecho Internacional la elaboración de un proyecto de Estatuto para la creación de un tribunal penal internacional con carácter permanente. (Naciones Unidas, 1993, p. 2).

\begin{abstract}
Por lo tanto, a la hora de hacer un análisis del Estatuto de Roma, no se puede desconocer que el proyecto de código de crímenes contra la paz y la seguridad de la humanidad y el proyecto de Estatuto de una corte penal internacional, fueron creados en momentos, circunstancias y épocas diferentes, mediante comisiones distintas. Asimismo, el Grupo de Trabajo encargado de estudiar el proyecto de Estatuto, decidió no ocuparse de cuestiones de derecho sustancial, y por ende se limitó al derecho procesal, la parte administrativa, la creación de una Fiscalía de la corte penal internacional y las funciones de esta, entre otros temas (Hoyos, 2012, p. 61; Naciones Unidas, 1994, p. 201).
\end{abstract}

Lo anterior es de significativa relevancia, pues al no haberse realizado un trabajo conjunto, mancomunado o continuado, con apreciación de las dificultades, los detalles y los problemas superados, era supremamente factible que se presentaran varias inconsistencias. Es decir, cuando los redactores del proyecto de Estatuto para la creación de un tribunal penal internacional, decidieron omitir lo que venía realizando la Comisión para la creación del proyecto de código de crímenes contra la paz y la seguridad de la humanidad, optaron por desconocer y omitir el trabajo y los 
alcances realizados por esta Comisión, concretamente sobre el criterio de gravedad, el cual se encontraba dentro de los elementos de los crímenes. (Hoyos, 2012, p. 61)

Ahora bien, la Comisión para la creación del proyecto de Estatuto, decidió incorporar un artículo en el cual se establecían unos criterios de admisibilidad para que el tribunal penal internacional pudiera conocer de una determinada situación, esto fue por razones políticas. El criterio de admisibilidad, estaba sustentado de tal manera que podía y buscaba la forma de persuadir para que los Estados aceptaran dicho Estatuto y firmaran su adhesión. (Naciones Unidas, 1994, p. 201; Hoyos, 2012, p. 61).

No obstante, el argumento mediante el cual se sustentó la necesidad del artículo sobre las cuestiones de admisibilidad, radicaba en que para la Comisión era necesario expresar que únicamente los crímenes más graves podían ser juzgados por el tribunal penal internacional; asimismo, tanto los Estados como los individuos podían impugnar la competencia del tribunal para conocer de un caso determinado, ya sea porque este no era objeto de la relevancia necesaria para la comunidad internacional o porque estaba siendo objeto de investigación por el Estado competente. (Naciones Unidas, 1994, p. 203).

Indicó la Comisión, que con el artículo 35 (De las cuestiones de admisibilidad) se buscaba que el Tribunal solo se ocupará de aquellos casos en los que se daban las circunstancias que se exponen en el preámbulo, es decir, cuando sea realmente deseable su intervención (Naciones Unidas, 1994, Vol. II, p. 55). Es decir, que para que el Tribunal decidiera si un caso era o no admisible tenía que tomar en consideración los propósitos del Estatuto que se encuentran establecidos en el Preámbulo. (Hoyos, 2012, p. 62; Naciones Unidas, 1994, Vol. II, p. 55).

Por lo anterior, el estudio del criterio de gravedad suficiente debe realizarse de conformidad con los intereses fundamentales tutelados por el Estatuto de Roma. (Hoyos, 2012, p. 63)

$\mathrm{Al}$ respecto, es importante señalar que el numeral 1 literal d del artículo 15 que hace referencia al umbral de gravedad suficiente, en un pie de página dice: "Algunas delegaciones consideraron que este apartado debería incluirse en otra parte del Estatuto o suprimirse" (Conferencia Diplomática de Plenipotenciarios de las Naciones Unidas para el establecimiento de una corte penal internacional, 1998, p. 41; Hoyos, 2012, p. 63). 
De esta manera, vale la pena analizar nuevamente la viabilidad del criterio de la gravedad suficiente del artículo 17 (1) (d) del Estatuto de Roma a través de su desarrollo, y la utilidad que ha prestado para la Corte Penal Internacional y la Oficina del Fiscal. (Hoyos, 2012, p. 63)

En todo caso, es de resaltar que los fines del proyecto de código y del proyecto de Estatuto, según quedó plasmado posteriormente en el preámbulo del Estatuto de Roma en su inciso tercero, es la protección de los intereses fundamentales de "la paz, la seguridad y el bienestar de la humanidad". (Estatuto de Roma, 2013; Hoyos, 2012, p. 63)

\section{El umbral de gravedad suficiente en la doctrina}

Sobre el umbral de gravedad suficiente del artículo 17 (1) (d), Werle (2011, p. 172) afirmó: "Los tribunales nacionales conservan competencia (exclusiva) respecto de hechos que no exceden de un cierto umbral de gravedad $^{11}$; respecto de estos casos no es admisible la sustanciación de un proceso ante la Corte Penal Internacional".

Asimismo, tanto Kai Ambos, como otros autores, han resaltado la crítica realizada principalmente por Schabas, respecto de dar por sentada la gravedad en situaciones como las de la República Democrática del Congo, Uganda y Sudán, sin embargo, en situaciones como las de Irak, realizó estudios más profundos rechazando la gravedad de conformidad con el artículo 53 (1) (b), teniendo en cuenta el número relativamente bajo de víctimas en los crímenes presuntamente cometidos por las tropas británicas comparado con la violencia a gran escala de las situaciones provenientes de la República Democrática del Congo, Uganda y Sudán (Ambos, 2010, p. 10). A lo anterior Schabas (citado por Ambos, 2010) criticó lo mencionado, señalando que eso era como "manzanas con naranjas" (p. 11).

Ahora bien, "[e]1 art. 29 no 2 del finalmente aprobado reglamento de la Oficina del Fiscal se refiere a la evaluación de la gravedad de las 'situaciones' a 'varios

\footnotetext{
${ }^{1}$ Señala Werle (2011): De conformidad con el art. 17.1. d) del Estatuto de la CPI, la sustentación de un proceso ante la Corte Penal Internacional no es admisible cuando "[e]1 asunto no sea de gravedad suficiente para justificar la adopción de otras medidas por la Corte. De acuerdo con la Sala de Cuestiones Preliminares de la CPI, el art. $17.1 \mathrm{~d}$ ) debe asegurar que la Corte solo sustanciará procesos en contra de los principales involucrados ("most senior leaders"), respecto de quienes se sospeche que tienen la responsabilidad del más alto nivel en crímenes de derecho internacional (p. 172).
} 
factores', incluyendo su magnitud, naturaleza, modo de comisión, e impacto" (Ambos, 2010, p. 11).

Al respecto, Ambos desarrolla cada uno de los conceptos de magnitud, naturaleza, modo de comisión, e impacto, y para efectos del presente estudio basta con señalar que lo anterior no resuelve las críticas que se le han hecho a la Sala de Cuestiones Preliminares, y por el contrario, ha agudizado la problemática porque como bien señalaba Schabas, no se puede comparar manzanas con naranjas, en el entendido de que los crímenes son muy diversos, tienen muchas modalidades, en ocasiones, matices, por lo que darle cabida a lo señalado, desconocería lo que Ramelli (2011) llamó "Las cláusulas-umbral de gravedad: elemento material" donde expone los elementos de los crímenes de lesa humanidad, donde el umbral de gravedad está inmerso como más adelante se explicará.

Por otro lado, la Sala de Cuestiones Preliminares II, en la situación de la República de Kenia ha señalado que la gravedad de las situaciones debe ser analizada teniendo en cuenta los casos potenciales que puedan llegar a surgir de la situación. De esta manera, este análisis se debe realizar considerando i) el grupo de personas que sería objeto de investigación "aquellos que pueden ser los presuntos máximos responsables de los crímenes”; ii) un análisis de la gravedad de los crímenes cometidos teniendo en cuenta la naturaleza, su escala, modo de comisión, impacto sobre las víctimas y la existencia de agravantes (Olásolo, 2011, p. 176).

Es importante resaltar que tanto en la doctrina como en la jurisprudencia hay un cierto acuerdo, aunque no absoluto, en señalar que dentro del umbral de gravedad se encuentran los máximos responsables, sin embargo, se considera que esto aplica principalmente para los crímenes de guerra, toda vez que son los "dirigentes" militares quienes dan el curso de la guerra, permiten y dan cabida a los excesos. No obstante, en los crímenes de lesa humanidad y genocidio, si bien pueden ser importantes los dirigentes, no se cree que sea esencial, pues estos crímenes tienen otros elementos que los componen, la simple ejecución de conductas que puedan enmarcarse dentro de todos los elementos de los crímenes de lesa humanidad o genocidio, será de gravedad suficiente, si esa misma conducta, afecta los intereses fundamentales de la paz, la seguridad y el bienestar de la humanidad (Hoyos, 2012).

Asimismo, Olásolo (2011) afirma:

[L]a Sala de Cuestiones Preliminares II ha desperdiciado una gran oportunidad para aclarar el alcance del umbral de gravedad previsto en el art. 17 (1) (d) del ER, 
en particular cuando se aplica a situaciones, sobre todo si tenemos en cuenta que la Sala de Apelaciones, a pesar de no haber adoptado el criterio de "los líderes de más alto rango sospechosos de ser los máximos responsables”, no ha proporcionado hasta el momento un criterio alternativo para examinar dicho umbral de gravedad (p. 177).

El problema del umbral de gravedad suficiente como requisito de admisibilidad del art. 17 (1) (d), sigue vigente y no ha sido abordado todavía a profundidad, como ha señalado Olásolo.

\section{La Corte Penal Internacional}

A lo largo del estudio, se pudo establecer que los redactores del proyecto de código de crímenes contra la paz y la seguridad de la humanidad, determinaron unos elementos mediante los cuales se podía establecer si ciertos actos podían constituir crímenes de competencia de la Corte por su gravedad. (Hoyos, 2012, p. 64).

Lo precedente se puede evidenciar en la forma como están planteados los diferentes crímenes en los artículos 6, 7 y 8 del Estatuto de Roma, los cuales se componen por unas condiciones o un contexto que implanta unos elementos o requisitos que se tienen que dar para que las conductas subsiguientes puedan constituir ya sea, crímenes de genocidio, lesa humanidad o guerra, respectivamente.

Así, para el crimen de lesa humanidad

El artículo 7 del Estatuto de Roma, está compuesto de una definición general que comporta los elementos de contexto, para que las conductas subsiguientes cumplan los requisitos necesarios para que puedan ser catalogadas de crímenes de lesa humanidad. De esta manera, son crímenes de lesa humanidad "cualquiera de los actos siguientes cuando se cometa como parte de un ataque generalizado o sistemático contra una población civil y con conocimiento de dicho ataque”. (Estatuto de Roma, 2012; Hoyos, 2012, p. 64)

Ahora bien, para el crimen de guerra señaló que: "La Corte tendrá competencia respecto de los crímenes de guerra en particular cuando se cometan como parte de un plan o política o como parte de la comisión en gran escala de tales crímenes” (Estatuto de Roma, 2012). 
No obstante, en la decisión de confirmación de cargos contra Jean-Pierre Bemba Gombo, la Sala de Cuestiones Preliminares II, determinó que el término "en particular" del artículo 8 (1) hacía claridad en que la existencia de un plan, política o la comisión a gran escala no era un prerrequisito para que la Corte ejerciera su jurisdicción sobre los crímenes de guerra, sino que servían como pautas prácticas para la Corte. (Hoyos, 2012, p. 74; ICC, Pre-Trial Chamber II, 2009, § 211).

\section{El umbral de gravedad en la Sala de Cuestiones Preliminares}

La Sala de cuestiones preliminares, al revisar el caso de Thomas Lubanga Dyilo, realizó el primer estudio y antecedente respecto del criterio de la gravedad suficiente, en dicha solicitud de arresto, la Sala de Cuestiones Preliminares sostuvo:

Concluye la Sala aduciendo que considera que cualquier caso derivado de una investigación ante la Corte, va a satisfacer el umbral de gravedad provisto por el artículo 17 (1) (d) del Estatuto, si puede responder afirmativamente a las siguientes preguntas:

1. ¿La conducta que es objeto de un caso es sistemática o generalizada? Debido a las consideraciones dadas debería causar una alarma social en la comunidad internacional por la relevancia del tipo de conducta.

2. Considerando la posición de la persona en la entidad del Estado, la organización o el grupo armado a que él ha pertenecido, ¿puede ser considerado que la persona cae dentro de la categoría de los mayores líderes de la situación bajo investigación?

3. ¿Cae la persona dentro de la categoría de uno de los principales líderes sospechosos de ser uno de los mayores responsables, considerando i) el papel jugado por la persona a través de acciones u omisiones cuando la entidad del Estado, la organización o los grupos armados a que él pertenecía cometieron crímenes dentro de la jurisdicción de la Corte, y ii) el rol jugado por tal entidad del Estado, organización o grupo armado en la totalidad de la comisión de los crímenes dentro de la jurisdicción de la corte en la situación pertinente? (ICC, Pre-Trial Chamber I, 2006, § 56). 
Ahora bien, en la decisión de apertura de investigación en la República de Kenia, la Sala de Cuestiones Preliminares, señaló:

Al hacer esta valoración, la Sala consideró que la gravedad podía ser examinada siguiendo los alcances cuantitativos y cualitativos. Con respecto a la dimensión cualitativa, no es el número de víctimas lo que importa, es más bien la existencia de algunas agravantes o factores cualitativos anexos a la comisión de los crímenes, que lo hacen grave. Cuando se considera la gravedad de los crímenes, puede haber varios factores concernientes sobre la sentencia como los reflejados en la Regla 145xiv (1) (c) y (2) (iv) de las Reglas de Procedimiento y prueba, que podrían proveer una guía útil en tal examinación. Estos factores podrían ser resumidos como: i) la escala de los presuntos crímenes; ii) la naturaleza de la ilicitud de la conducta o de los crímenes presuntamente cometidos; iii) los medios empleados para la comisión de los crímenes, por ejemplo, la manera en que se cometieron los crímenes; y iv) el impacto de los crímenes y los daños causados a las víctimas y sus familias. (ICC, Pre-Trial Chamber II, 2010, § 62).

No se está de acuerdo con esta postura adoptada por la Sala de Cuestiones Preliminares en la decisión de apertura de investigación en la República de Kenia, toda vez que no parece viable solucionar un problema de apertura de investigación en un país con las agravantes a imponer a un individuo ya condenado, porque son dos momentos completamente diferentes, y con fines distintos.

\section{Conclusiones}

El criterio de gravedad como se analizó, se compone de un elemento subjetivo y otro objetivo. El subjetivo, se encuentra en el móvil, en la intención del autor, sin embargo, la Comisión también resaltó que dentro del elemento subjetivo, se encuentra

[L]a crueldad o barbarie del crimen; o de la amplitud de sus efectos, como el carácter masivo de los crímenes; o por su intención, tal como requiere el crimen de genocidio. En todo caso, estos crímenes vulneran los fundamentos de las sociedad humana. (Naciones Unidas, 1987, Vol. II, p. 2; Hoyos, 2012, p. 39) 
Por otro lado, el elemento objetivo se encuentra en los intereses fundamentales tutelados por el Estatuto de Roma. Es decir, si se cometen conductas de conformidad con los elementos de contexto y aquellas conductas vulneran los intereses fundamentales del inciso tercero del preámbulo, se estaría, por ende, frente a crímenes de competencia de la Corte.

\section{Referencias}

Ambos, K. (2010). El teste de complementariedad de la Corte Penal Internacional (artículo 17 Estatuto de Roma). InDret 2/2010. Recuperado de http://www.indret.com/ pdf/727.pdf

Cryer, R., Friman, H., Robinson, D., Wilmshurst, E. (2007). An Introduction to International Criminal Law and Procedure. New York: Cambridge University Press.

Hoyos, M. (2012). El umbral de gravedad suficiente del Artículo 17 (1) (d) del Estatuto de Roma. Tesis de grado para optar al título de Abogado. Universidad Santo Tomás, Bogotá, Colombia.

Olásolo, H. (2011). Ensayos de derecho penal y procesal internacional. Biblioteca Jurídica Diké.

Ramelli, A. (2011). Jurisprudencia penal internacional aplicable en Colombia. Uniandes

Schabas, W. (2007). An Introduction to the International Criminal Court. New York: Cambridge University Press.

Werle, G. (2011). Tratado de Derecho Penal Internacional. Editorial Tirant Lo Blanch. Valencia.

\section{Tesis no publicada}

Ramírez, S. (2012). La Paz y el Crimen de Agresión. Proyecto preliminar de la Tesis de grado para optar al título de Magister. Universidad Santo Tomás en convenio con la Universidad de Salamanca, Bogotá, Colombia.

\section{Documentos jurídicos}

Comité Internacional de la Cruz Roja (1949). III. Convenio de Ginebra relativo a los prisioneros de guerra. Recuperado el 15 de septiembre de 2011, de http://www.icrc.org/spa/ resources/documents/treaty/treaty-gc-3-5tdkwx.htm

Comité Internacional de la Cruz Roja (1977). Protocolo I adicional a los convenios de ginebra de 1949 relativo a la protección de las víctimas de los conflictos armados 
internacionales. Recuperado el 15 de septiembre de 2011, dehttp://www.icrc.org/spa/ resources/documents/misc/protocolo-i.htm

ICC. Pre-Trial Chamber I (2006). Situation in the Democratic Republic of the Congo in the case of Prosecutor v. Thomas LubangaDyilo. Decision on the Prosecutor's Application for a warrant of arrest, Article 58.ICC-01/04-01/06-8-US-Corr.

ICC. Pre-Trial Chamber II (2009). Situation in the Central African Republic in the case of Prosecutor v. Jean-Pierre Bemba Gombo. Decision Pursuant to Article 61 (7)(a) and (b) of the Rome Statute on the Charges of the Prosecutor Against Jean-Pierre Bemba Gombo. ICC-01/05-01/08-424.

ICC. Pre-Trial Chamber II (2010). Situation in the Republic of Kenya. Decision Pursuant to Article 15 of the Rome Statute on the Authorization of an investigation into the situation in the Republic of Kenya. ICC-01/09-19.

Naciones Unidas. (1951). Documents of the third session including the report of the Comission to the General Assambly. Yearbook of the International Law Commission (1951). Vol. II, 133 - 139. Recuperado 10 de septiembre del 2011, de http://untreaty. un.org/ilc/publications/yearbooks/Ybkvolumes(e)/ILC_1951_v2_e.pdf

Naciones Unidas (1976). Informe de la Comisión a la Asamblea General sobre la labor realizada en su vigésimo octavo período de sesiones. Anuario de la Comisión de Derecho Internacional. Volumen II. Segunda parte. Páginas 94. A/CN.4/SER.A/1976/ Add.1 (Part 2). Recuperado el 13 de noviembre del 2011, de http://untreaty.un.org/ ilc/publications/yearbooks/Ybkvolumes(s)/ILC_1976_v2_p2_s.pdf

Naciones Unidas (1983). Actas resumidas de las sesiones del trigésimo quinto período de sesiones 3 de mayo - 22 de junio de 1983. Anuario de la Comisión de Derecho Internacional, Volumen I, Páginas 3 - 46, 296 - 311, 338 - 344. A/CN.4/SER.A/1983. Recuperado el 8 de septiembre de 2011, de http://untreaty.un.org/ilc/publications/ yearbooks/Ybkvolumes(s)/ILC_1983_v1_s.pdf

Naciones Unidas (1983). Documentos del trigésimo quinto período de sesiones. Anuario de la Comisión de Derecho Internacional. Anuario de la Comisión de Derecho Internacional. Volumen II. Primera parte. Páginas 147 - 164. A/CN.4/SER.A/1983/Add.1 (Part 1). Recuperado el 8 de septiembre de 2011, de http://untreaty.un.org/ilc/publications/ yearbooks/Ybkvolumes(s)/ILC_1983_v2_p1_s.pdf

Naciones Unidas (1984). Actas resumidas de las sesiones del trigésimo sexto período de sesiones 7 de mayo - 27 de julio de 1984. Anuario de la Comisión de Derecho Internacional. Volumen I, Páginas 4 - 58. A/CN.4/SER.A/1984. Recuperado el 8 de septiembre de 2011, de http://untreaty.un.org/ilc/publications/yearbooks/Ybkvolumes(s)/ILC_1984_v1_s.pdf 
Naciones Unidas (1984). Documentos del trigésimo sexto período de sesiones. Anuario de la Comisión de Derecho Internacional. Anuario de la Comisión de Derecho Internacional. Volumen II. Primera parte. Páginas 93 - 105. A/CN.4/SER.A/1984/Add.1 (Part 1). Recuperado el 8 de septiembre de 2011, de http://untreaty.un.org/ilc/publications/ yearbooks/Ybkvolumes(s)/ILC_1984_v2_p1_s.pdf

Naciones Unidas (1985). Documentos del trigésimo séptimo período de sesiones. Anuario de la Comisión de Derecho Internacional. Anuario de la Comisión de Derecho Internacional. Volumen II. Primera parte. Páginas 65 - 86. A/CN.4/SER.A/1985/Add.1 (Part 1). Recuperado el 8 de septiembre de 2011, de http://untreaty.un.org/ilc/publications/ yearbooks/Ybkvolumes(s)/ILC_1985_v2_p1_s.pdf

Naciones Unidas (1986). Actas resumidas de las sesiones del trigésimo octavo período de sesiones 5 de mayo - 11 de julio de 1986. Anuario de la Comisión de Derecho Internacional. Volumen I, Páginas 91 - 196, 295 - 298, 304. A/CN.4/SER.A/1986. Recuperado el 8 de septiembre de 2011, de http://untreaty.un.org/ilc/publications/ yearbooks/Ybkvolumes(s)/ILC_1986_v1_s.pdf

Naciones Unidas (1987). Actas resumidas de las sesiones del trigésimo noveno período de sesiones 4 de mayo - 17 de julio de 1987. Anuario de la Comisión de Derecho Internacional. Volumen I, Páginas 4 - 67, 240 - 254, 268 - 276. A/CN.4/SER.A/1987. Recuperado el 8 de septiembre de 2011, de http://untreaty.un.org/ilc/publications/ yearbooks/Ybkvolumes(s)/ILC_1987_v1_s.pdf

Naciones Unidas (1987). Documentos del trigésimo noveno período de sesiones. Anuario de la Comisión de Derecho Internacional. Anuario de la Comisión de Derecho Internacional. Volumen II. Primera parte. Páginas 1 - 13. A/CN.4/SER.A/1987/Add.1 (Part 1). Recuperado el 8 de septiembre de 2011, de http://untreaty.un.org/ilc/publications/ yearbooks/Ybkvolumes(s)/ILC_1987_v2_p1_s.pdf

Naciones Unidas (1989). Actas resumidas de las sesiones del cuadragésimo primer período de sesiones 4 de mayo - 17 de julio de 1987. Anuario de la Comisión de Derecho Internacional. Volumen I, Páginas 4 - 47, 71 - 85, 306 - 321, 369 - 381. A/CN.4/ SER.A/1987. Recuperado el 8 de septiembre de 2011, de http://untreaty.un.org/ilc/ publications/yearbooks/Ybkvolumes(s)/ILC_1989_v1_s.pdf

Naciones Unidas (1989). Documentos del cuadragésimo primer período de sesiones. Anuario de la Comisión de Derecho Internacional. Anuario de la Comisión de Derecho Internacional. Volumen II. Primera parte. Páginas 85 - 94. A/CN.4/SER.A/1989/Add.1 (Part 1). Recuperado el 8 de septiembre de 2011, de http://untreaty.un.org/ilc/publications/ yearbooks/Ybkvolumes(s)/ILC_1989_v2_p1_s.pdf 
Naciones Unidas (1993). Resolución aprobada por la Asamblea General. Informe de la Comisión de Derecho Internacional sobre la labor realizada en su $44^{\circ}$ período de sesiones. A/RES/47/33. Recuperado el 28 agosto del 2012, de http://daccess-dds-ny.un.org/doc/ UNDOC/GEN/N93/086/71/IMG/N9308671.pdf?OpenElement

Naciones Unidas (1994). Actas resumidas de las sesiones del cuadragésimo sexto período de sesiones 2 de mayo - 22 de julio de 1994. Anuario de la Comisión de Derecho Internacional. Volumen I, Páginas 3 - 15, 16 - 41, 116 - 140, 147 - 157, 204 - 212, 214 - 233, 237 - 243, 308 - 320, 321 - 325. A/CN.4/SER.A/1994. Recuperado el 7 de septiembre de 2011, dehttp://untreaty.un.org/ilc/publications/yearbooks/ Ybkvolumes(s)/ILC_1994_v1_s.pdf

Naciones Unidas (1994). Informe de la Comisión a la Asamblea General sobre la labor realizada en su cuadragésimo sexto período de sesiones. Anuario de la Comisión de Derecho Internacional. Volumen II. Segunda parte. Páginas 19 - 93. A/CN.4/SER.A/1994/ Add.1 (Part 2). Recuperado el 7 de septiembre de 2011, de http://untreaty.un.org/ilc/ publications/yearbooks/Ybkvolumes(s)/ILC_1994_v2_p2_s.pdf

Naciones Unidas (1996). Actas resumidas de las sesiones del cuadragésimo octavo período de sesiones 6 de mayo - 26 de julio de 1996. Anuario de la Comisión de Derecho Internacional. Volumen I, Páginas 8 - 15, 33 - 49, 51 - 133, 152 - 161, 219 - 243, 279 - 286, 290 - 291. A/CN.4/SER.A/1996. Recuperado 10 de mayo del 2012, de http://untreaty.un.org/ilc/publications/yearbooks/Ybkvolumes(s)/ILC_1996_v1_s.pdf

Naciones Unidas (1996). Informe de la Comisión a la Asamblea General sobre la labor realizada en su cuadragésimo octavo período de sesiones. Anuario de la Comisión de Derecho Internacional. Volumen II. Segunda parte, Páginas 17 - 62. A/CN.4/ SER.A/1996/Add.1 (Part 2). Recuperado el 11 de mayo del 2012, de http://untreaty. un.org/ilc/publications/yearbooks/Ybkvolumes(s)/ILC_1996_v2_p2_s.pdf

Naciones Unidas (1998). Conferencia Diplomática de Plenipotenciarios de las Naciones Unidas sobre el establecimiento de una penal internacional. A/CONFIG.183/2/Add.1 Recuperado 14 de mayo del 2012, de http://daccess-dds-ny.un.orOTg/doc/UNDOC/ GEN/N98/101/08/PDF/N9810108.pdf?OpenElement

Naciones Unidas (2013). Estatuto de Roma. Recuperado 23 de febrero del 2012, de http://www.icc-cpi.int/NR/rdonlyres/ADD16852-AEE9-4757-ABE7-9CDC7CF02886/283783/Compendium3rd01SPA.pdf 